NOC 技術ノートNo. 267

\title{
EPDM 用混合加硫促進剤
}

\section{ノクセラー EP-90 について（4）}

EPDM の加硫系としては, 各加工メーカーそれ ぞれ の加工条件（加硫速度, 物性など）に合った加硫系を選 択し, 数種類の加硫促進昘を併用している場合が多い. このため, 混合加硫促進剂（ノクセラー EP-55, EP-90 など）に切り替える場合に，加硫速度・物性が若干異な る場合も生じる.このような場合には, 混合加硫促進剤 に更にほかの加硫促進剤を併用寸ることによって, 加硫 速度・物性を調節することができる。

混合加硫促進羭のノクセラー EP-90は, 押出し製品に 充分使用できるよらに，特に耐スコーチ性を重点に開発 したものであり，ノクセラー EP-55に比べると加硫速度 が遅く, また加硫物の引張応力が低い欠点が 挙 げられ る.

\section{実験}

1. 配 合

EPDM（中不飽和度）

100 酸化悪鉛

ステアリン酸

$\mathrm{FEF}$ ブラック

パイフィン系油

硫黄

加硫促進剂試料

別記

2. ムーニースコーチ試験

JIS K 6300 に準拠, $\mathrm{ML}_{-1}\left(125^{\circ} \mathrm{C}\right)$

\begin{tabular}{|c|c|c|c|c|c|}
\hline & 試 & 料 & $V_{m}$ & $t_{5}$ & $t_{\Delta 30}$ \\
\hline 1. & \multicolumn{2}{|c|}{ EP-90(4) } & 52 & $15^{\prime} 50^{\prime \prime}$ & $7^{\prime} 30^{\prime \prime}$ \\
\hline 2. & " & ("I) $+\mathrm{M}-60(1)$ & 53 & $7^{\prime} 50^{\prime \prime}$ & $4^{\prime} 00^{\prime \prime}$ \\
\hline 3. & " & $($ (I) $)+\mathrm{CZ}(1)$ & 51 & $14^{\prime} 00^{\prime \prime}$ & $7^{\prime} 30^{\prime \prime}$ \\
\hline 4. & $" \prime$ & $(\prime \prime)+\operatorname{TRA}(1)$ & 52 & $12^{\prime} 45^{\prime \prime}$ & $7^{\prime} 10^{\prime \prime}$ \\
\hline 5. & $"$ & $($ (I) $)+\mathrm{BZ}(1)$ & 51 & $11^{\prime} 45^{\prime \prime}$ & $6^{\prime} 30^{\prime \prime}$ \\
\hline 6. & " & $(\prime \prime)+\operatorname{TTFE}(1)$ & 53 & $10^{\prime} 20^{\prime \prime}$ & $5^{\prime} 25^{\prime \prime}$ \\
\hline 7. & $" \prime$ & $(\prime \prime)+\mathrm{EGS} *(1)$ & 52 & $9^{\prime} 05^{\prime \prime}$ & $3^{\prime} 35^{\prime \prime}$ \\
\hline 8. & EP-9 & $0(6)$ & 52 & $13^{\prime} 55^{\prime \prime}$ & $8^{\prime} 15^{\prime \prime}$ \\
\hline 9. & EP-5 & $5(3)$ & 54 & $9^{\prime} 10^{\prime \prime}$ & $4^{\prime} 55^{\prime \prime}$ \\
\hline 10. & $\mathrm{TS}(1$ & $.5)+\mathrm{M}(0.5)$ & 50 & $20^{\prime} 00^{\prime \prime}$ & $11^{\prime} 00^{\prime \prime}$ \\
\hline
\end{tabular}

*ノックマスター EGS: 加硫活性剂
今回も前回に引き続ぎ EPDM 用混合加硫促進斉のノ クセラー EP-90（ 4 phr 配合）に，更にノクセラーM60， GZ，TRA， BZ，TTFE 及びノックマスターEGS （加硫活性剂）をそれぞれ $1 \mathrm{phr}$ 併用した場合の加硫性 能について紹介する.

併用した場合のレオメータ加硫曲線を図 1 に示した.

ノクセラーM-60, ノックマスターEGS, ノクセラー TTFE，ノクセラー BZ を併用すると加硫速度が速くな ることがわかる.

また，引張応力を高めるには（5. 引張試験から），， クセラー TRA, BZ の併用が良いことがわかる.

加硫促進剂のノクセラー EGS の併用は, 加硫速度は 速くなるが加硫物の引張応力を低下させる.

また，ノクセラーTTFE の併用は，加硫速度及び引張 応力も高めるが，加硫物にブルームが認められ．また白 色製品, 明色製品などには着色性があるために,ノクセラ － EP-90 に併用する加硫促進剤としては好ましくない.

\section{3. レオメータ試験}

モンサント ODR, 振幅角 $1^{\circ}$, 振動数 $100 \mathrm{cpm}$

\begin{tabular}{|c|c|c|c|c|c|}
\hline 試 & $\begin{array}{l}\text { 試験温 } \\
\text { 度 }\left({ }^{\circ} \mathrm{C}\right)\end{array}$ & $\begin{array}{c}\mathbf{M}_{\mathbf{L}} \\
{[\mathrm{N} \cdot \mathrm{m}]}\end{array}$ & $\begin{array}{r}\mathrm{M}_{\mathbf{H F}} \\
{[\mathrm{N} \cdot \mathrm{m}]}\end{array}$ & $t^{\prime} \mathbf{C}_{(10)}$ & $t^{\prime} \mathbf{C}(90)$ \\
\hline \multirow{2}{*}{$\begin{array}{l}\text { 1. EP-90 } \\
(4)\end{array}$} & 160 & 0.69 & 4.03 & $3^{\prime} 10^{\prime \prime}$ & $15^{\prime} 40^{\prime \prime}$ \\
\hline & 180 & 0.62 & 3.82 & $1^{\prime} 35^{\prime \prime}$ & $6^{\prime} 05^{\prime \prime}$ \\
\hline \multirow{2}{*}{$\begin{array}{l}\text { 2. EP-90+M-60 } \\
\begin{array}{ll}(4) & (1)\end{array}\end{array}$} & 160 & 0.70 & 4.02 & $2^{\prime} 10^{\prime \prime}$ & $14^{\prime} 00^{\prime \prime}$ \\
\hline & 180 & 0.62 & 3.82 & $1^{\prime} 10^{\prime \prime}$ & $5^{\prime} 25^{\prime \prime}$ \\
\hline 3. $\mathrm{EP}-90+\mathrm{CZ}$ & 160 & 0.69 & 4.12 & $3^{\prime} 30^{\prime \prime}$ & $14^{\prime} 00^{\prime \prime}$ \\
\hline (4) (1) & 180 & 0.62 & 3.95 & $1^{\prime} 40^{\prime \prime}$ & $530^{\prime \prime}$ \\
\hline 4. EP-90+TRA & 160 & 0.69 & 4.29 & $2^{\prime} 50^{\prime \prime}$ & $13^{\prime} 20^{\prime \prime}$ \\
\hline (4) (1) & 180 & 0.62 & 4.21 & $1^{\prime} 35^{\prime \prime}$ & $6^{\prime} 00^{\prime \prime}$ \\
\hline 5. $\quad \mathrm{EP}-90+\mathrm{BZ}$ & 160 & 0.69 & 4.11 & $2^{\prime} 40^{\prime \prime}$ & $12^{\prime} 40^{\prime \prime}$ \\
\hline$(4) \quad(1)$ & 180 & 0.62 & 3.97 & $1^{\prime} 25^{\prime \prime}$ & $5^{\prime} 10^{\prime \prime}$ \\
\hline 6. EP-90+TTFE & 160 & 0.71 & 4.23 & $2^{\prime} 40^{\prime \prime}$ & $11^{\prime} 00^{\prime \prime}$ \\
\hline (4) (1) & 180 & 0.63 & 4.14 & $1^{\prime} 25^{\prime \prime}$ & $4^{\prime} 40^{\prime \prime}$ \\
\hline 7. $\mathrm{EP}-90+\mathrm{EGS}$ & 160 & 0.69 & 4.02 & $2^{\prime} 20^{\prime \prime}$ & $15^{\prime} 10^{\prime \prime}$ \\
\hline (4) (1) & 180 & 0.62 & 3.77 & $1^{\prime} 20^{\prime \prime}$ & $5^{\prime} 30^{\prime \prime}$ \\
\hline 8. $\quad$ EP-90 & 160 & 0.69 & 4.06 & $3^{\prime} 10^{\prime \prime}$ & $13^{\prime} 10^{\prime \prime}$ \\
\hline (6) & 180 & 0.62 & 3.85 & $1^{\prime} 35^{\prime \prime}$ & $6^{\prime} 05^{\prime \prime}$ \\
\hline \multirow{2}{*}{ 9. EP-55 } & 160 & 0.71 & 4.28 & $2^{\prime} 10^{\prime \prime}$ & $11^{\prime} 40^{\prime \prime}$ \\
\hline & 180 & 0.64 & 4.15 & $1^{\prime} 10^{\prime \prime}$ & $4^{\prime} 55^{\prime \prime}$ \\
\hline \multirow{2}{*}{$\begin{array}{r}\text { 10. TS }+M \\
(1.5)(0.5) \\
\end{array}$} & 160 & 0.68 & 4.20 & $3^{\prime} 50^{\prime \prime}$ & $13^{\prime} 10^{\prime \prime}$ \\
\hline & 180 & 0.60 & 4.03 & $1^{\prime} 55^{\prime \prime}$ & $5^{\prime} 30^{\prime \prime}$ \\
\hline
\end{tabular}




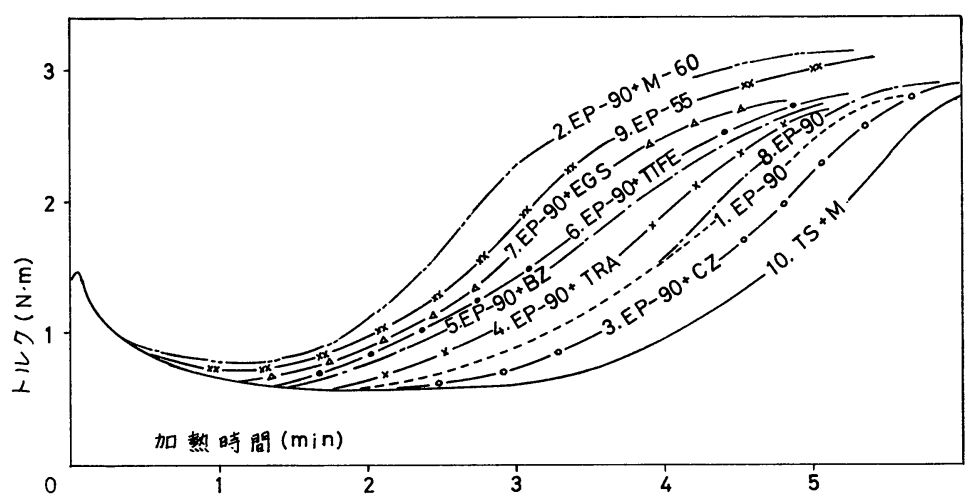

図 1 レオメータ加硫曲線, モンサント ODR, $160^{\circ} \mathrm{C}$

\section{4. 耐スコーチ性試験}

[評価方法]

未加硫ゴムをギアーオーブン中で $100{ }^{\circ} \mathrm{C} \times 60$ 分間熱処 理した後, レオメータ加硫試験機で最小トクル值 $\left(\mathrm{M}_{\mathbf{L}}{ }^{\prime}\right)$ を測定した. トルク上昇率が小さいほど耐スコーチ性良 好と判断した.

モンサント ODR, $160^{\circ} \mathrm{C}, 100 \mathrm{cpm}$

\begin{tabular}{|c|c|c|c|c|c|}
\hline & 試 & 料 & $\begin{array}{c}\text { 熱処理前 } \\
M_{L} \\
{[\mathrm{~N} . \mathrm{m}]}\end{array}$ & $\begin{array}{c}\text { 熱処理後 } \\
\mathbf{M}_{\mathbf{L}}^{\prime} \\
{[\mathrm{N} . \mathrm{m}]}\end{array}$ & $\begin{array}{l}\text { トルク } \\
\text { 上昇率* } \\
\text { [\%] }\end{array}$ \\
\hline 1. & \multicolumn{2}{|c|}{$\mathrm{EP}-90(4)$} & 0.69 & 0.86 & 25 \\
\hline 2. & $" \prime$ & $(\prime \prime)+\mathrm{M}-60(1)$ & 0.70 & 1.66 & 137 \\
\hline 3. & $"$ & $(\prime \prime)+\mathrm{CZ}(1)$ & 0.69 & 0.86 & 25 \\
\hline 4. & " & $(\prime \prime)+\operatorname{TRA}(1)$ & 0.69 & 0.99 & 43 \\
\hline 5. & " & $($ (I) $)+\mathrm{BZ}(1)$ & 0.69 & 0.98 & 42 \\
\hline 6. & " & $(\prime \prime)+\operatorname{TTFE}(1)$ & 0.71 & 1.30 & 83 \\
\hline 7. & $"$ & $(\prime \prime)+\operatorname{EGS}(1)$ & 0.69 & 1.39 & 101 \\
\hline 8. & EP-9 & $(6)$ & 0.69 & 0.85 & 23 \\
\hline 9. & $\mathrm{EP}-5$ & $5(3)$ & 0.71 & 1.60 & 125 \\
\hline 10. & $\operatorname{TS}(1$. & 5) $+M(0.5)$ & 0.68 & 0.79 & 16 \\
\hline
\end{tabular}

\section{5. 引張試験}

JIS K 6301-’75 に準拠，プレス加硫 $160^{\circ} \mathrm{C}$

\begin{tabular}{|c|c|c|c|c|c|c|}
\hline 試 & 料 & $\begin{array}{l}\text { 妿硫時 } \\
\text { 間 (分) }\end{array}$ & $\begin{array}{c}T_{B} \\
{[\mathrm{MPa}]}\end{array}$ & $\begin{array}{r}E_{B} \\
{[\%]}\end{array}$ & $\begin{array}{r}M_{300} \\
{[\mathrm{MPa}]}\end{array}$ & $\left.\stackrel{H_{S}}{\mathrm{JIS}} \mathrm{A}\right]$ \\
\hline \multirow{2}{*}{\multicolumn{2}{|c|}{$\begin{array}{l}\text { 1.EP-90 } \\
\text { (4) }\end{array}$}} & 15 & 13.7 & 390 & 11.4 & 75 \\
\hline & & 20 & 13.4 & 350 & 12.5 & 75 \\
\hline \multicolumn{2}{|c|}{ 2. $\mathrm{EP}-90+\mathrm{M}-60$} & 15 & 13.8 & 390 & 11.5 & 76 \\
\hline (4) & (1) & 20 & 14.0 & 380 & 12.2 & 76 \\
\hline \multicolumn{2}{|c|}{ 3. EP-90+CZ } & 15 & 13.1 & 380 & 11.2 & 76 \\
\hline (4) & (1) & 20 & 13.7 & 370 & 11.9 & 76 \\
\hline \multicolumn{2}{|c|}{ 4. EP-90+TRA } & 15 & 14.1 & 350 & 13.0 & 77 \\
\hline \multicolumn{2}{|c|}{ (4) (1) } & 20 & 14.3 & 340 & 13.6 & 78 \\
\hline \multicolumn{2}{|c|}{ 5. $\mathrm{EP}-90+\mathrm{BZ}$} & 15 & 14.2 & 360 & 12.7 & 76 \\
\hline \multirow{2}{*}{\multicolumn{2}{|c|}{$\frac{(4) \quad(1)}{6 . \quad \text { EP-90+TTFE }}$}} & 20 & 14.3 & 340 & 13.4 & 76 \\
\hline & & 15 & 14.0 & 350 & 12.8 & 78 \\
\hline \multicolumn{2}{|c|}{ (4) (1) } & 20 & 14.6 & 330 & 14.0 & 78 \\
\hline \multicolumn{2}{|c|}{ 7. EP-90+EGS } & 15 & 13.2 & 430 & 10.4 & 75 \\
\hline (4) & (1) & 20 & 13.4 & 400 & 10.9 & 75 \\
\hline \multicolumn{2}{|c|}{ 8. EP-90 } & 15 & 14.1 & 390 & 12.1 & 76 \\
\hline \multicolumn{2}{|c|}{ (6) } & 20 & 13.8 & 380 & 12.7 & 77 \\
\hline
\end{tabular}

\begin{tabular}{llllll} 
9. $\mathrm{EP}-55$ & 15 & 15.0 & 320 & 14.4 & 76 \\
(3) & 20 & 15.2 & 290 & - & 76 \\
\hline $\begin{array}{c}\text { 10. TS }+\mathrm{M} \\
\text { (1.5) }(0.5)\end{array}$ & 15 & 14.3 & 350 & 13.2 & 75 \\
\end{tabular}

\section{6. ブルーム性試験}

$160^{\circ} \mathrm{C} \times 20$ 分プレス加硫物を $23{ }^{\circ} \mathrm{C}$, 湿度 $50 \%$ で放置

$$
\text { [ブルーム性の評価] }
$$

$\bigcirc$ :ブルーム無し, $\times$ : ブルーム有り $\times \times \times$ : 全面ブルーム

\begin{tabular}{|c|c|c|c|c|c|c|}
\hline \multicolumn{2}{|r|}{ 試 } & 料 & \multicolumn{2}{|c|}{ 放置日数(日) - } & 30日 & $\overline{60}$ \\
\hline 1. & EP-90 & $(4)$ & 0 & 0 & 0 & 0 \\
\hline 2. & " & $($ (I) $)+M-60(1)$ & 0 & 0 & 0 & 0 \\
\hline 3. & " & $(\prime \prime)+\mathrm{CZ}(1)$ & 0 & 0 & 0 & 0 \\
\hline 4. & " & $(")+$ TRA (1) & 0 & 0 & 0 & 0 \\
\hline 5. & " & $($ (I) $+\mathrm{BZ}(1)$ & 0 & 0 & 0 & 0 \\
\hline 6. & " & ("I) + TTFE (1) & $x$ & $x \times$ & $x \times$ & $x \times$ \\
\hline 7. & " & $(\prime \prime)+\operatorname{EGS}(1)$ & 0 & 0 & 0 & 0 \\
\hline 8. & EP-90 & $(6)$ & 0 & 0 & 0 & 0 \\
\hline 9. & EP-55 & (3) & 0 & 0 & 0 & 0 \\
\hline 10. & $\mathrm{TS}(1.5$ & ) $+\mathrm{M}(0.5)$ & $x$ & $x \times$ & $x \times$ & $x \times$ \\
\hline
\end{tabular}

\section{7. 熱老化及び圧縮永久ひずみ試験}

JIS K 6301 に準拠， $160^{\circ} \mathrm{C} \times 20$ 分プレス加硫物 熱老化： $120^{\circ} \mathrm{C} \times 70 \mathrm{~h}$ ，ギアー式老化試験機 圧縮永久ひずみ $(\mathrm{C} \mathrm{S}): 100^{\circ} \mathrm{C} \times 22 \mathrm{~h}$

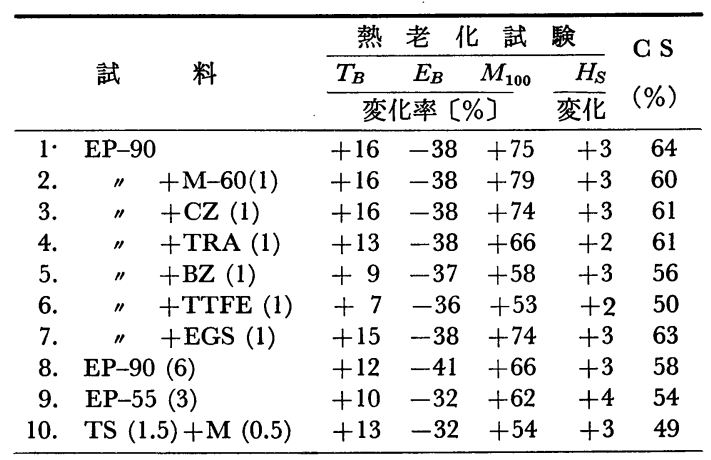

